\title{
Size-Selectivity Of The Northwest Atlantic Sea Scallop (Placopecten Magellanicus) Dredge
}

\author{
Noelle Yochum \\ Virginia Institute of Marine Science \\ William D. DuPaul \\ Virginia Institute of Marine Science
}

Follow this and additional works at: https://scholarworks.wm.edu/vimsarticles

Part of the Marine Biology Commons

\section{Recommended Citation}

Yochum, Noelle and DuPaul, William D., "Size-Selectivity Of The Northwest Atlantic Sea Scallop (Placopecten Magellanicus) Dredge" (2008). VIMS Articles. 436.

https://scholarworks.wm.edu/vimsarticles/436 


\title{
SIZE-SELECTIVITY OF THE NORTHWEST ATLANTIC SEA SCALLOP (PLACOPECTEN MAGELLANICUS) DREDGE
}

\author{
NOËLLE YOCHUM ${ }^{1,2 *}$ AND WILLIAM D. DUPAUL ${ }^{1}$ \\ ${ }^{1}$ Virginia Institute of Marine Science, College of William and Mary, P.O. Box 1346, Gloucester Point, VA \\ 23062; ${ }^{2}$ Present address: Moss Landing Marine Laboratories, 8272 Moss Landing Rd, Moss Landing, \\ CA 95039
}

\begin{abstract}
A size-selectivity curve was constructed to characterize the performance of the New Bedford style Atlantic sea scallop (Placopecten magellanicus, Gmelin 1791) dredge when it is configured to meet the requirements of Amendment \#10 to the Sea Scallop Fishery Management Plan. The curve was generated using the SELECT model on catch-at-length data, obtained by simultaneously towing a New Bedford style dredge and a nonselective National Marine Fisheries Service sea scallop survey dredge from commercial scallop vessels. Data were collected during three cruises in the Northwest Atlantic between 2005 and 2006. The resultant selectivity curve yielded a $50 \%$ retention length of $100.1 \mathrm{~mm}$, a selection range of $23.6 \mathrm{~mm}$, and a value of 0.77 for the efficiency of the commercial dredge relative to the survey dredge. A length of $100.1 \mathrm{~mm}$ corresponds to a meat weight of $17.2 \mathrm{~g}$ in Georges Bank and $16.8 \mathrm{~g}$ in the mid-Atlantic. These results can assist fisheries managers with stock assessments, fishing mortality estimates, and the interpretation of catch data from resource surveys. Additionally, the curve can be used as a baseline to evaluate the effect of future changes to sea scallop dredge configuration.
\end{abstract}

KEY WORDS: Size-selectivity, Placopecten magellanicus, sea scallop, fisheries, dredge

\section{INTRODUCTION}

The Atlantic sea scallop (Placopecten magellanicus) supports the second most profitable fishery in the United States. In 2006, 59 million pounds of meats were landed yielding an exvessel value of \$386 million US dollars (Van Voorhees 2007). To ensure the sustainability of the industry and the scallop population, substantial effort has been directed to the management of this resource. Whereas many factors that affect the health of the sea scallop stock are out of human control, fisheries managers have a variety of tools to control anthropogenic impacts. One management strategy is to use area closures and gear restrictions to delay age at recruitment into the fishery. By reducing fishing mortality on younger, smaller scallops, there is the potential to substantially increase yield-per-recruit in future landings and to increase the population's total reproductive output. Although scallops begin to spawn after the deposition of their first growth ring (Naidu 1969, Langton et al. 1987), egg production increases exponentially with shell height (Langton et al. 1987). Additionally, between the ages of 2 and 6 shell height doubles in Georges Bank and the midAtlantic and meat weight increases 7-fold in the mid-Atlantic and 8-fold in Georges Bank (NEFSC 2007).

The Sea scallop fishery management plan (SSFMP) regulates the configuration of the commercial fishing gear to minimize the capture of under sized scallops (NEFMC 1982). Past restrictions for the offshore New Bedford style dredge (Fig. 1) include minimum mesh size restrictions for the twine top, as well as restrictions on the use of chafing gear and on the internal diameter and spacing of the rings. Under the most recent modification (Amendment \#10) to the SSFMP, offshore scallop dredges are required to use twine tops with a minimum stretched mesh size of $254 \mathrm{~mm}$; restrict chafing gear to the bottom of the dredge; use rings with a minimum internal diameter of $102 \mathrm{~mm}$; and use no more than double links between rings, except on the dredge bottom where a maximum

\footnotetext{
*Corresponding author. E-mail: noelle_yochum@yahoo.com
}

of triple links may be used (NEFMC 2003). With the passing of Amendment \#10 in 2003, it became necessary to determine how a gear configured with these specifications would perform and if it would attain the goal of selecting against smaller scallops.

Size-selectivity curves have the potential to address both of these questions because they model the probability that a sea scallop of length $l$, if contacting the gear, will be retained (Millar 1992). This curve can also assist fisheries managers to translate survey abundance into expected yield and can provide insight into how the gear is interacting with scallops of a given length. Additionally, because gear selectivity measurements are used in connection with fishing mortality calculations, this information can assist fisheries managers in performing stock assessments (Wileman et al. 1996). Furthermore, a selection curve is a component of yield-per-recruit analyses and can be used to estimate population length frequency (Millar \& Fryer 1999).

Several studies have been conducted to evaluate the performance of the New Bedford style ("commercial") dredge relative to another selective gear (Bourne 1965, Caddy 1972, DuPaul \& Kirkley 1994, Brust et al. 1995, Rudders et al. 1998, Rudders et al. 2000, Goff 2002) and a previous study assessed the selectivity of the commercial dredge configured with $89 \mathrm{~mm}$ rings (NEFSC 2004). An absolute size-selectivity curve for this gear, configured to meet current management requirements, has not been created. To do this, catch from the commercial (experimental) gear must be compared with that from a nonselective (control) gear. With these data, the Share Each LEngth's Catch Total (SELECT) model developed by Millar (1992) can be used to generate this curve. This model has been successful with evaluating the selection properties of fishing gear, including: traps, dredges, hooks, and nets (trawl, gill, and seine) (Millar 1992, Millar \& Walsh 1992, Xu \& Millar 1993, Millar \& Holst 1997, Millar \& Fryer 1999, Revill \& Holst 2004, Gálvez \& Rebolledo 2005, Mituhasi et al. 2005).

The SELECT model has become the preferred method for evaluating gear selectivity because it is biologically meaningful 

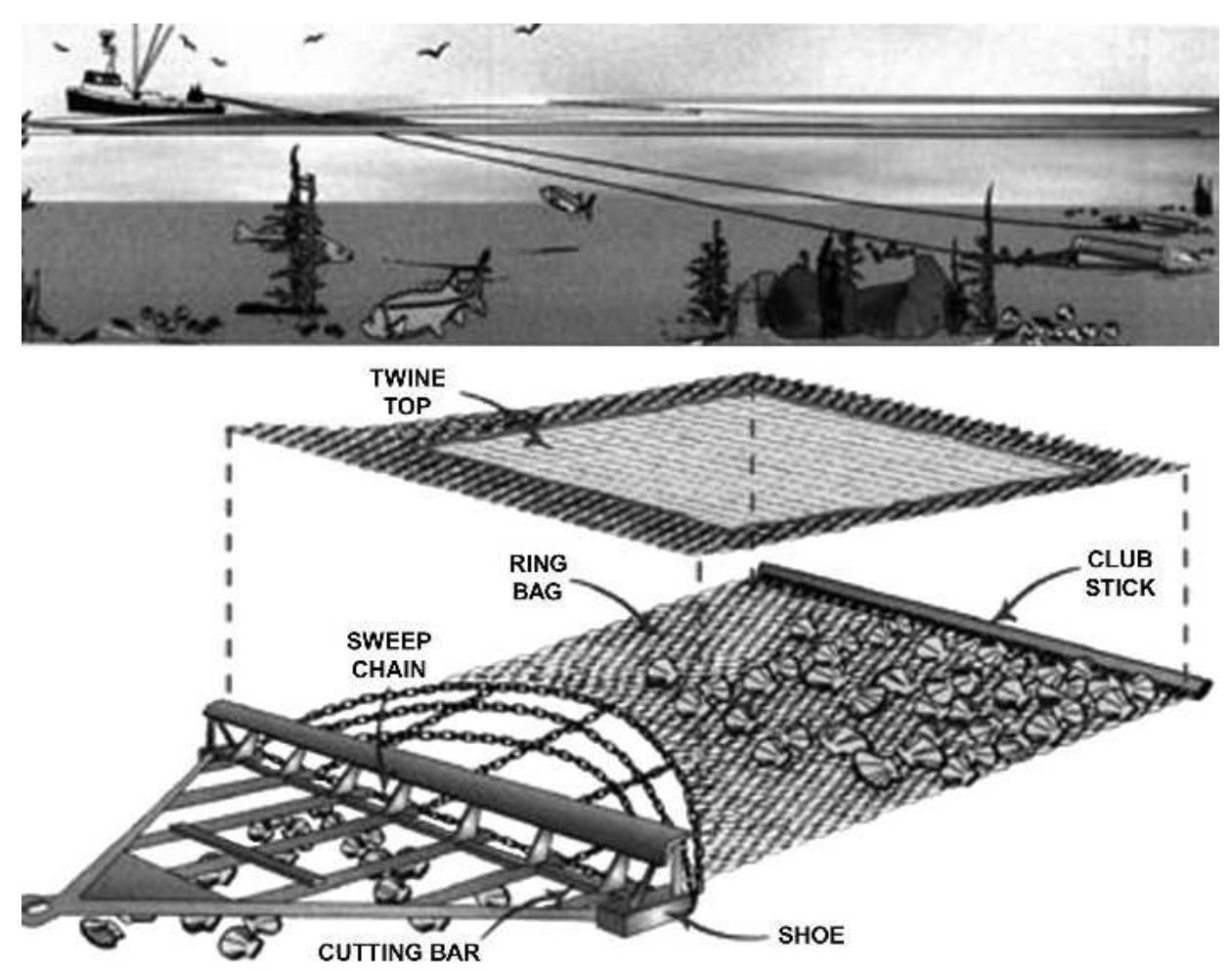

Figure 1. The New Bedford style sea scallop dredge with the top removed for illustration. This diagram is courtesy of Coonamessett Farm. Image drawn by Robin Amaral.

and does not require knowledge of the actual population length distribution. Also, the SELECT model incorporates a parameter that denotes relative fishing intensity between two gears (experimental and control). This is the split parameter, $p_{j}$, which accounts for how catch among gears $(j=1, \ldots, \mathrm{n})$ will vary because of affects such as differential fishing effort, fish avoidance behavior, and localized fish concentrations (Millar 1992). In addition to estimating $p_{j}$, the SELECT model can be used to estimate two other factors often used to characterize selection. These are: the $50 \%$ retention length $\left(l_{50}\right)$, the length at which a scallop has a $50 \%$ probability of being retained after entering the gear, and the selection range (SR), the difference between the $75 \%$ and $25 \%$ retention lengths $\left(l_{75}-l_{25}\right)$, which is a measure of how quickly $100 \%$ retention is approached (i.e., the steepness of the curve).

The objective of this study is to use the SELECT model to generate a size-selectivity curve for the offshore New Bedford style sea scallop dredge consistent with the requirements of Amendment \#10 to the SSFMP. To accomplish this, catch from the commercial dredge was compared with that from the National Marine Fisheries Service (NMFS) survey ("survey") dredge, which served as the control gear in this study. The survey dredge is assumed to be effectively nonselective because there is a $38 \mathrm{~mm}$ polyethylene mesh liner sewn into the dredge bag, which prohibits small scallops from escaping.

To create a selectivity curve that is representative of the offshore commercial fleet, sampling was conducted aboard commercial scallop vessels, under conditions that approximated commercial practices and was completed during different months and in different areas. The spatial variation encompassed a wide range of substrates as well as differing densities and size distributions of scallops. The only aspect of this study that is not representative of commercial practices is tow duration; however, an assessment of how the quantity of scallops and trash caught in the commercial dredge affects the parameters of the selectivity curve was made. This served as a proxy for how tow duration might affect the selection process. It must be noted, though, that tow duration does not predict the size of the catch.

\section{MATERIALS AND METHODS}

\section{Data Collection}

In August, September, and October of 2005 and in June of 2006; four cruises were completed aboard commercial sea scallop vessels: two in Georges Bank [one in the Nantucket Lightship Closed Area (NLCA), one in the Groundfish Closed Area II (CA2)], and two in the mid-Atlantic [both in the Elephant Trunk Closed Area (ETCA)]. Within each area, predetermined stations, selected within a systematic random grid, were sampled. At each station, a standard NMFS survey dredge was towed simultaneously with a New Bedford style commercial sea scallop dredge. Simultaneously towing the two dredges from the same vessel allowed for similar type of substrate and population of scallops to be sampled. The survey dredge was $2.44 \mathrm{~m}$ in width, was configured $51 \mathrm{~mm}$ rings, an $89 \mathrm{~mm}$ diamond mesh twine top, and a $38 \mathrm{~mm}$ diamond mesh liner. The commercial dredges were $4.57 \mathrm{~m}$ in width, had $102 \mathrm{~mm}$ rings, a $254 \mathrm{~mm}$ mesh twine top and no liner. Some aspects of the commercial gear configuration varied on the different vessels used for this study (e.g., length of the sweep chain), but this is advantageous because this variation exists within the actual commercial fleet. Rock chains and chafing 
TABLE 1.

Information regarding valid tows used in the analyses as well as sampling stations and conditions.

\begin{tabular}{lcccc}
\hline \hline & NLCA & CA2 & ETCA & ETCA \\
Cruise & $\mathbf{2 0 0 5}$ & $\mathbf{2 0 0 5}$ & $\mathbf{2 0 0 5}$ & $\mathbf{2 0 0 6}$ \\
\hline Average station depth (fathoms) & 36 & 40 & 28 & 28 \\
Depth range of stations (fathoms) & $28-43$ & $32-51$ & $18-39$ & $20-38$ \\
Average minimum/maximum & $7 / 12$ & $9 / 15$ & $11 / 18$ & $11 / 17$ \\
$\quad$ wind speed (knots) & & & & \\
Average minimum/maximum sea state & $2 / 4$ & $2 / 4$ & $2 / 5$ & $3 / 5$ \\
Average tow duration (minutes) & 14.6 & 15.8 & 14.7 & 15.7 \\
$\begin{array}{l}\text { Average vessel speed (knots) } \\
\text { Average dredge wire scope }\end{array}$ & 3.8 & 3.8 & 3.8 & 3.8 \\
Number of tows used in the analysis & 3.1 & 3.1 & 3.0 & 3.0 \\
\hline
\end{tabular}

gear were used on both dredges as dictated by the area surveyed and current regulations.

The duration of each tow was approximately $15 \mathrm{~min}$ and towing speed was 3.8 knots. Depth range varied in each area; however, a 3:1 wire scope (the ratio of the amount of wire out to the vertical distance from the boat to the seafloor) was maintained for all tows (Table 1). To determine bottom contact time and to ensure that the gear was fishing correctly, an inclinometer (an instrument used to measure deviations from true vertical or horizontal) was attached to the survey dredge. High-resolution navigational logging equipment was used to document tow time, vessel position and speed, and course over ground. During each cruise the survey dredge was towed from the port side of the vessel for the first half of the stations and from the starboard side for the remainder to counteract any random effect associated with fishing from a particular side.

Upon completion of each tow, the entire catch from both gears was emptied on deck. Scallops were then sorted out of the catch and placed into baskets. The number of baskets from each side was counted and a subsample of these was measured. Shell height (the longest distance between the umbo and the ventral margin of the shell) measurements of the scallops were made in $5 \mathrm{~mm}$ increments on counting boards. Additionally, all bycatch was quantified and trash (anything other than scallops or finfish, including rocks and invertebrate bycatch) was volumetrically measured.

\section{Data Analysis}

Each tow was evaluated and deemed invalid if any of the following conditions were observed: gear hangs, flips, crossing or tangling, an inclinometer trace indicating that the gear was not fishing correctly, or fewer than 20 scallops were caught in either dredge. A catch of less than 20 suggests that there may not have been scallops present at the sampling location or scallops from a preceding tow may have been lodged in the dredge or left on deck.

The number of scallops caught per length class, from each gear, was multiplied by an expansion factor equal to the number of baskets of scallops caught divided by the number of baskets measured. The tows were then combined by cruise, closed area, year, and all tows from the CA2 and the two ETCA cruises together (Data from the NLCA cruise were excluded because the gears used during this survey were different than those used during the other cruises). For each tow and combination of tows, the ratio of the number of scallops in each length class in the commercial dredge to the total in both dredges (Commercial/ Total) was plotted to determine if the commercial gear was behaving selectively. This assessment validated proceeding with the analysis.

The catch-at-length data for each tow combination were then analyzed with the SELECT model (Millar 1992). This model equates the proportion of scallops (of length $l$ ) that are caught in the commercial gear out of the total catch from both gears $\left(\Phi_{c}(l)\right)$ to:

$$
\text { 1. } \Phi c(l)=\frac{p_{c} r_{c}(l)}{p_{c} r_{c}(l)+\left(1-p_{c}\right)}
$$

Selectivity of the commercial gear, $r_{c}(l)$, is the probability that a scallop of length $l$ will be retained given that it contacts the gear and the split parameter, $p_{c}$, describes the relative fishing intensity or relative efficiency of the commercial dredge (Millar 1992). Dredge selectivity tends to reflect the logistic function; however, alternative models (e.g., the Richards, log-log and complementary-log-log curves) may also be appropriate. An examination of the deviance residuals and the Akaike Information Criterion (AIC) may be used to determine the most appropriate model. If selection of the commercial gear follows the logistic model, it is equal to:

$$
\text { 2. } r_{c}(l)=\frac{\exp (a+b l)}{1+\exp (a+b l)}
$$

Substituting this into the SELECT model yields:

$$
\text { 3. } \Phi_{c}(l)=\frac{p_{c} \exp (a+b l)}{\left(1-p_{c}\right)+\exp (a+b l)}
$$

where $a$ and $b$ are the logistic selectivity parameters and $p_{c}$ is the split-parameter. Estimates of these parameters were generated by maximizing the likelihood:

$$
\begin{aligned}
& \text { 4. } L(a, b, p c \mid \text { data })= \\
& \prod_{l=7.5}^{177.5}\left(\frac{p c \exp (a+b l)}{(1-p c)+\exp (a+b l)}\right)^{C_{C}}\left(1-\frac{p c \exp (a+b l)}{(1-p c)+\exp (a+b l)}\right)^{C_{S}}
\end{aligned}
$$

$C_{C}$ is the number of length $l$ scallops in the commercial gear and $C_{S}$ is the number of length $l$ scallops in the survey gear. The lengths $(l)$ are the midpoints of each length class (i.e., length "7.5 mm" represents the length class $5-10 \mathrm{~mm}$ ). To generate the selectivity curve, estimated values for parameters $a$ and $b$ are reinserted into the logistic equation (Eq. 2). The resultant curve is symmetric about the $l_{50}$ and the slope is determined by the selection range. The $l_{50}$ and the SR relate to parameters $a$ and $b$ by:

$$
\text { 5. } S R=\frac{2 \ln (3)}{b} \text { and } 6 . l_{50}=\frac{-a}{b}
$$

The data were evaluated using the R-Statistical Program for Windows as well as in Excel using the Solver function.

Because of variation in wind speed, water depth, sea state, scallop density, and other factors that cannot be controlled, there is variation in selectivity from one tow to the next. This must be considered when tows are combined. A test for 
overdispersion (variation exceeding that which is predicted by the model) was completed using the replication estimate of between-haul variation (REP) combined hauls approach discussed in Millar et al. 2004. REP is the Pearson chi-square statistic for model goodness of fit divided by the degrees of freedom, which is the number of terms in the summation minus the number of fitted parameters. If the null hypothesis that there is no extra variation is rejected then REP provides an estimate of the overdispersion and the standard errors of the parameters are multiplied by the square root of REP (Millar et al. 2004). To avoid over-inflating the degrees of freedom for this analysis, only length classes where, when all tows are combined, one dredge has caught at least 20 scallops were used. To determine if this affected the estimated parameters, the model was run under this criterion as well as under the criteria that, for each length class, at least one dredge had more than: (1) zero scallops, (2) 60 scallops, and (3) 1,000 scallops. In general, with fewer length classes used in the analysis, the $50 \%$ retention length, selection range, split parameter, and log likelihood values all increased; however, these changes were negligible.

The final analysis was to evaluate the effect of increased trash and scallop catch on the estimated selectivity parameters. This approximated how the results for this study might have been influenced by the short $(15 \mathrm{~min})$ tow duration (as compared with longer commercial tows). This ensures that the resultant selectivity curve is representative of commercial practices. For this assessment, tows from all three cruises were grouped into five categories based on the number of baskets of scallops caught in the commercial dredge: (1) fewer than three, (2) three to six, (3) 6 to 12, (4) 12 to 24, and (5) more than 24. These increments were chosen because there was a similar number of tows that fit into each group. A selectivity curve was generated for each category, using the same length classes that were used to evaluate all tows combined. A Spearman's rank correlation coefficient analysis was then completed on the resulting $l_{50}$, SR and $p_{c}$ values. This procedure was repeated with increasing baskets of trash. Categories for this analysis were based on the number of baskets of trash in the commercial dredge: (1) $<0.25$, (2) 0.25 to one, (3) one, (4) one to two, and (5) more than two.

\section{RESULTS AND DISCUSSION}

The catch-at-length data obtained during this study were evaluated with the SELECT model using the logistic as well as Richards, log-log and complementary-log-log curves to determine the most appropriate model for the data. The deviance residuals from the logistic fit showed no subjective trends and that the curve adequately fit the data. The other three models did not significantly improve the fit, based on AIC values. The results will only be presented for the logistic SELECT model. The REP assessment for combining multiple tows indicated extra variation for all tow combinations (by cruise, year, area and the CA2 and two ETCA cruises combined), therefore, standard errors for the estimated parameters were multiplied by the square root of REP (Millar et al. 2004).

Estimated parameters are given in Table 2 and the fitted curves and deviance residuals are shown in Figure 2. A common feature for all tow combinations is that at the largest sizes the proportion caught in the commercial dredge decreases. This caused a pattern in the residuals, namely that residuals at the larger lengths are negative. This is not of concern because the data points for these sizes are influenced by only a handful of tows, which makes them susceptible to outlying information. For example, the " $152.5 \mathrm{~mm}$ " data point for the ETCA 2005 SELECT curve is influenced primarily by two tows, which had only a few scallops at that length in the survey dredge and none in the commercial. When these data were multiplied by the expansion factor the discrepancy between the two dredges was exaggerated. Additionally, patterns in the residuals attributed to this are not significant because when these outlying length classes were removed there is no considerable change in the estimated parameter values.

The $a$ and $b$ parameters estimated for each combination of tows were inserted into the logistic selectivity curve equation (Eq. 2). The range of $l_{50}$ values from the different combinations

TABLE 2.

Estimated parameters from the logistic SELECT analyses on catch-at-length data for all length classes with at least 20 scallops in one of the dredges. Listed are lengths used in the analyses and the starting values to estimate the parameters in both $R$ and Excel. The estimated values (left column) for logistic parameters $a$ and $b$, as well as the $50 \%$ retention length $\left(l_{50}\right)$, the selection range (SR $\left.=l_{75}-l_{25}\right)$ and the relative efficiency split parameter $\left(p_{c}\right)$ are given. The number of tows (No. Tows) used for each analysis, log likelihood (L), and the replication estimate of between-haul variation (REP) are specified as well as the standard errors (right column), which have been multiplied by the square root of REP.

\begin{tabular}{|c|c|c|c|c|c|c|c|c|c|c|c|c|}
\hline & \multicolumn{2}{|l|}{ CA2 2005} & \multicolumn{2}{|c|}{ ETCA 2005} & \multicolumn{2}{|c|}{ ETCA 2006} & \multicolumn{2}{|c|}{ CA2 \& ETCA 2005} & \multicolumn{2}{|c|}{$\begin{array}{c}\text { ETCA } \\
2005 \& 2006\end{array}$} & \multicolumn{2}{|c|}{$\begin{array}{c}\text { CA2 2005, ETCA } \\
2005 \& 2006\end{array}$} \\
\hline Lengths & $47.5-162.5$ & & $22.5-152.5$ & & $27.5-152.5$ & & $22.5-162.5$ & & $22.5-157.5$ & & $22.5-162.5$ & \\
\hline $\begin{array}{l}\text { Start } \\
\text { values }\end{array}$ & $(-13,0.13,0.8)$ & & $(-10,0.1,0.75$ & & $(-12,0.12,0.8)$ & & $(-11,0.11,0.8)$ & & $(-12,0.12,0.8)$ & & $(-12,0.12,0.8$ & \\
\hline$a$ & -12.42 & & -10.85 & & -7.97 & & -11.46 & & -8.90 & & -9.32 & \\
\hline$b$ & 0.12 & & 0.11 & & 0.08 & & 0.12 & & 0.09 & & 0.09 & \\
\hline$p_{c}$ & 0.76 & 0.005 & 0.77 & 0.006 & 0.80 & 0.007 & 0.76 & 0.004 & 0.79 & 0.005 & 0.77 & 0.004 \\
\hline$l_{50}(\mathrm{~mm})$ & 105.16 & 1.11 & 96.42 & 0.94 & 104.14 & 1.30 & 98.09 & 0.63 & 101.44 & 0.80 & 100.11 & 0.60 \\
\hline $\mathrm{SR}_{(\mathrm{mm})}$ & 18.61 & 0.91 & 20.02 & 0.92 & 28.70 & 1.13 & 18.82 & 0.64 & 25.03 & 0.74 & 23.61 & 0.59 \\
\hline $\mathbf{L}$ & $-44,814$ & & $-92,396$ & & $-173,197$ & & $-137,452$ & & $-265,836$ & & $-311,035$ & \\
\hline REP & 4.54 & & 8.73 & & 8.51 & & 7.09 & & 8.79 & & 7.98 & \\
\hline No. tows & 54 & & 50 & & 69 & & 104 & & 119 & & 173 & \\
\hline
\end{tabular}



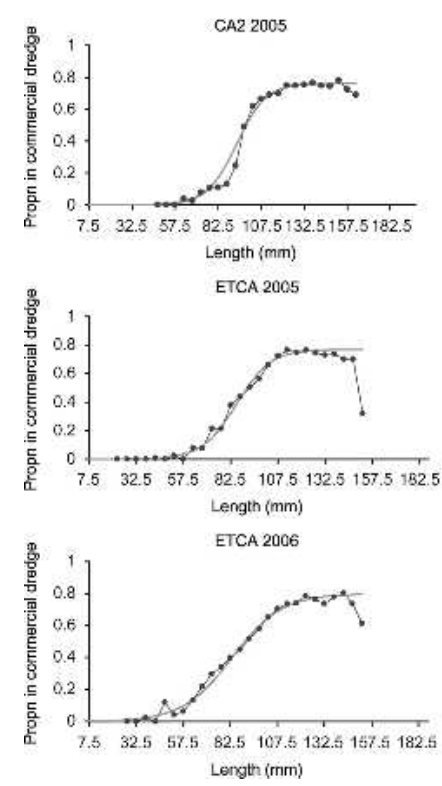
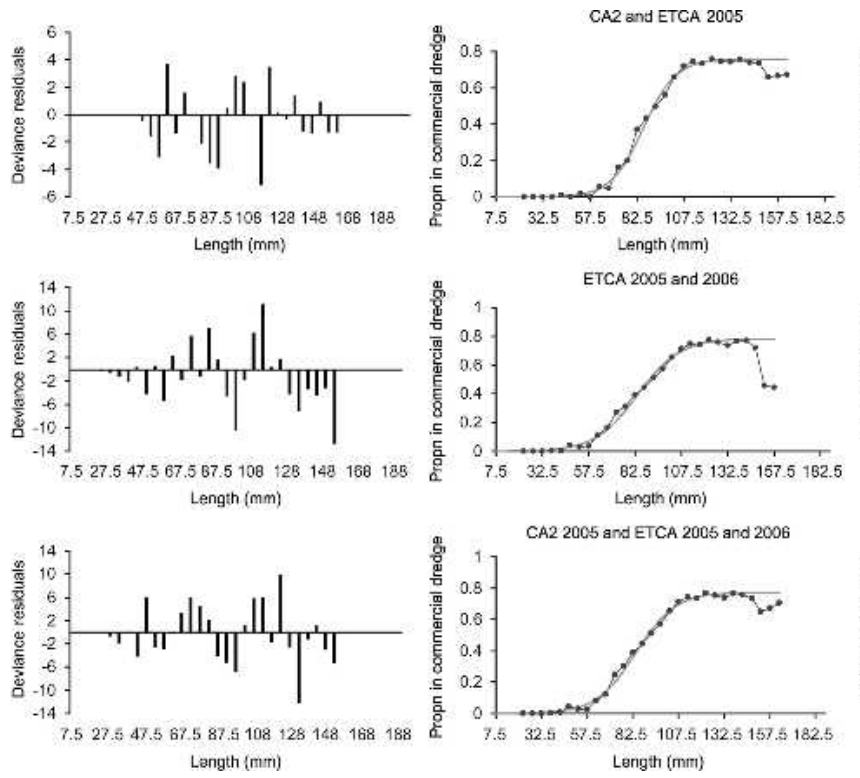

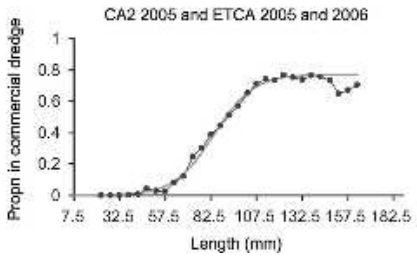

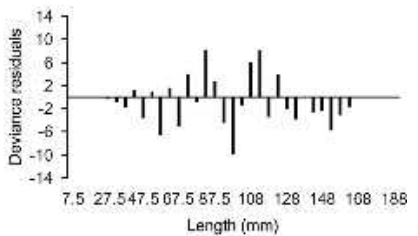
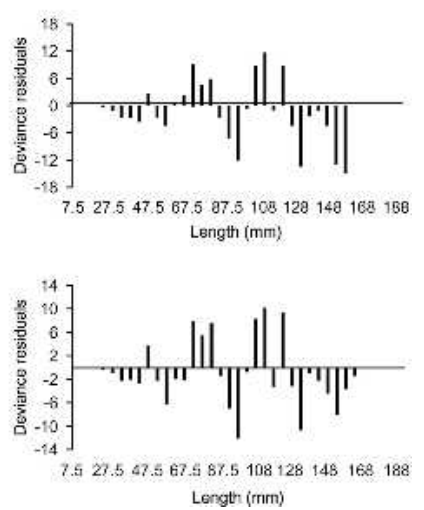

Figure 2. Logistic SELECT curves fitted to the proportion of the total catch in the commercial gear (left) and deviance residuals (right) for CA2 2005 , ETCA 2005, ETCA 2006, CA2 2005 and ETCA 2005 combined, ETCA 2005 and ETCA 2006 combined, and CA2 2005, ETCA 2005 and ETCA 2006 combined.

of data was 98.1-105.2 $\mathrm{mm}$ (a small difference of $7.1 \mathrm{~mm}$ ) and of selection range values was 18.6-28.7.

The final results are those that were estimated for all valid tows for the CA2 2005, ETCA 2005, and ETCA 2006 cruises combined. By including tows from multiple cruises on different vessels, during different times of the year and in different areas the selectivity curve becomes more representative of the commercial fleet. Also, additional data asymptotically promotes efficiency in parameter estimates. The resulting SR for this analysis is $23.6 \mathrm{~mm}$ and the $l_{50}$ is $100.1 \mathrm{~mm}$ (Fig. 3). The estimated split parameter is 0.77 , indicating that the commercial dredge is fishing more efficiently than the survey dredge. If the two gears were equally efficient, then the difference in the number of scallops entering the dredges would be a function of the width of the gears and the split parameter value for the commercial dredge would be equal to $\frac{4.57}{(4.57+2.44)}$ or 0.65 . However, the resulting value, 0.77 , indicates that other factors are affecting efficiency. A possibility, based on a study conducted by Serchuk and Smolowitz (1980) (and corroborated in NEFSC 2004), is that the liner decreases the efficiency of the survey dredge.

To combine the tows from two or more different cruises for the analysis it was imperative that the gears be the same throughout. Gear configuration was consistent for the Closed Area II (CA2) cruise in 2005 and for the cruises in the Elephant Trunk Closed Area (ETCA) in 2005 and 2006. Both the commercial and survey dredges used during the cruise in the Nantucket Lightship Closed Area (NLCA), however, were not equivalent. The hanging ratio and the size of the twine top on the survey dredge used in the NLCA were different from those used on the other cruises. The hanging ratio changed because, whereas the number of rings along the frame of the dredge remained the same for all cruises, the size of the twine top was
$25 \times 17$ meshes for the NLCA cruise and was $40 \times 15$ meshes for the others. Additionally, there was a reduced twine top surface area, and hence a tighter fit, in the NLCA survey dredge twine top because the dimensions $25 \times 17$ equate to a total of 425 meshes where a twine top with $40 \times 15$ has 600 . Furthermore, the commercial dredge in the NLCA differed in that it had a shorter twine top. As a result of these inconsistencies, the NLCA cruise was analyzed separately. Regardless, the final results were similar to those generated for the NLCA cruise alone. The estimated parameters for the NLCA cruise ( $a:-12.67$ and $b: 0.12)$ yielded a $50 \%$ retention length of $101.63 \mathrm{~mm}$, a selection range of $17.63 \mathrm{~mm}$ and a split parameter value of 0.76 . Standard errors for the estimated parameters were multiplied by the square root of REP because the data were overdispersed. An assessment of these parameters with

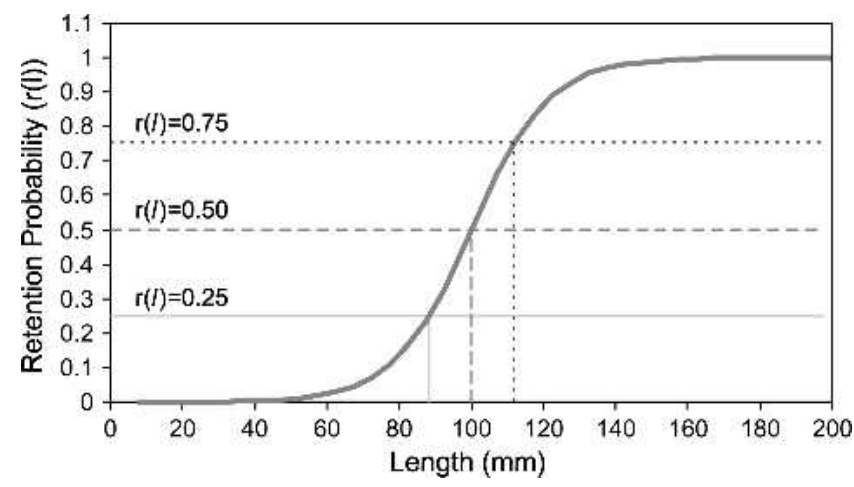

Figure 3. Logistic size-selection curve for the New Bedford style dredge, incorporating data from all valid tows from the CA2 2005, ETCA 2005 and ETCA 2006 cruises. The lengths at $25 \%, 50 \%$ and $75 \%$ probability of retention are shown. The selection range is the difference between the $\mathbf{7 5 \%}$ and $25 \%$ retention lengths $\left(l_{75}-l_{25}\right)$. 
confidence intervals reveals that there is no significant difference between the two 50\% retention lengths and split parameters, but that there is between the selection ranges. Regardless, the similarity of the results for the NLCA cruise and for the other cruises combined indicates that the selection curve generated for this study is robust to changes in gear configuration. Additionally, the length frequency distribution in the NLCA is quite different from the other closed areas. This implies that the selection curve is also robust to differences in length frequency distribution.

The NEFSC 2004 selectivity study determined that when the commercial dredge is configured with $89 \mathrm{~mm}$ rings it has a $l_{50}$ of $78.5 \mathrm{~mm}$. A scallop of this length would yield a meat weight of $8.4 \mathrm{~g}$ in Georges Bank and $7.7 \mathrm{~g}$ in the mid-Atlantic (NEFSC 2007). The commercial gear evaluated in this study had a $l_{50}$ of $100.1 \mathrm{~mm}$, which equates to a meat weight of $17.2 \mathrm{~g}$ in Georges Bank and $16.8 \mathrm{~g}$ in the mid-Atlantic (NEFSC 2007). This suggests that the current commercial gear design promotes increased yield-per-recruit. Additionally, the NEFSC 2007 growth parameters indicate that, in Georges Bank, a 100.1 $\mathrm{mm}$ scallop is $1.02 \mathrm{y}$ older than a $78.5 \mathrm{~mm}$ scallop and $1.05 \mathrm{y}$ older in the mid-Atlantic. Because the current gear delays entry into the fishery, harvested scallops have the potential to increase their spawning potential based on results from Langton et al. (1987) that indicate gamete production increases exponentially with shell height.

The final analysis was to evaluate how increases in the quantities of trash and scallops caught in the commercial dredge might affect the estimated selectivity parameters. This served as an approximation of whether the results were affected by the reduced tow duration used in this study. The Spearman's rank correlation coefficient significantly indicated that with increasing number of scallops the selection range and the split parameter values increase. Whereas the results for the $50 \%$ retention length appear to show a similar trend, the results were not significant. These results are not surprising because, as the volume of scallops increases there is increased potential for the rings and interrings spaces to clog, resulting in the retention of smaller scallops as well as of more scallops over all length classes. In contrast, none of the evaluated parameters showed a significant relationship with increasing number of baskets of trash. It can be assumed that the selectivity curve generated in this study does represent commercial practices, because there is not a significant difference in the $l_{50}$ values with increasing baskets of scallops or trash. Additionally, during the survey cruises, the dredge bag ranged from being empty to completely full, which mirrors the range observed during commercial operations.

Results from this study will benefit resource managers with stock assessments and with the forecast of future yield. Additionally, because a comparison between "selectivity curves for two different gear configurations is the only fully satisfactory means of describing how the gear selectivity has changed when developing new towed gears (Wileman et al. 1996)," the resultant selectivity curve will assist in predicting how potential changes to the dredge configuration might affect the resource and industry.

\section{ACKNOWLEDGMENTS}

This study would not have been possible without the assistance of David Rudders and the owners, captains and crew of the F/V Celtic, F/V Carolina Boy and F/V Westport. The authors also acknowledge Dvora Hart, John Hoenig, Russell Millar, and Paul Rago for their involvement with this study. The National Marine Fisheries Service Sea Scallop Research Set-Aside Program provided funding for this project. This is contribution number 2906 from the Virginia Institute of Marine Science.

\section{LITERATURE CITED}

Bourne, N. 1965. A comparison of catches by 3- and 4- inch rings on offshore scallop drags. J. Fish. Res. Board Canada 22:313333.

Brust, J. C., W. D. DuPaul \& J. E. Kirkley. 1995. Comparative efficiency and selectivity of 3.25 inch and 3.50 inch ring scallop dredges. Virginia Marine Resource Report No. 95-96. New England Fishery Management Council Sea Scallop Oversight Committee: June 25, 1995.

Caddy, J. F. 1972. Size selectivity of the Georges Bank offshore dredge and mortality estimate for scallops from the northern edge of Georges in the period June 1970 to 1971. ICNAF Redbook. pp. 79-85.

DuPaul, W. D. \& J. E. Kirkley. 1994. Harvest efficiency and size selectivity of 3.00 and 3.25 -inch sea scallop dredge rings. Marine Resource Report No. 94-95. Virginia Institute of Marine Science.

Gálvez, M. \& H. Rebolledo. 2005. Estimating codend size selectivity of bottom trawlnet in Chilean hake (Merluccius gayi gayi) fishery. Invest. Mar. Valparaiso 33:151-165.

Goff, K. D. 2002. Ring diameter and closed area scallop fisheries. Masters thesis, Virginia Institute of Marine Science, College of William and Mary.

Langton, R. W., W. E. Robinson \& D. Schick. 1987. Fecundity and reproductive effort of sea scallops Placopecten magellanicus from the Gulf of Maine. Mar. Ecol. Prog. Ser. 37:19-25.
Millar, R. B. 1992. Estimating the size-selectivity of fishing gear by conditioning on the total catch. J. Am. Stat. Assoc. 87:962-968.

Millar, R. B., M. K. Broadhurst \& W. G. Macbeth. 2004. Modeling between-haul variability in the size selectivity of trawls. Fish. Res. 67:171-181.

Millar, R. B. \& R. J. Fryer. 1999. Estimating the size-selection curves of towed gears, traps, nets and hooks. Rev. Fish Biol. Fish. 9:89116.

Millar, R. B. \& R. Holst. 1997. Estimation of gillnet and hook selectivity using log-linear models. ICES J. Mar. Sci. 54:471-477.

Millar, R. B. \& S. J. Walsh. 1992. Analysis of trawl selectivity studies with an application to trouser trawls. Fish. Res. 13:205220.

Mituhasi, T., T. Kitakado, F. Hu \& T. Tokai. 2005. Modeling the contact probability and size-selectivity of toothed dredges. Fish. Sci. 71:703-712.

Naidu, K. S. 1969. Growth, reproduction, and unicellular endosymbiotic alga in the giant scallop, Placopecten magellanicus (Gmelin), in Port au Port Bay, Newfoundland. M.Sc. Thesis, Memorial University of Newfoundland.

NEFMC (New England Fisheries Management Council). 1982. Fishery management plan. Final environmental impact statement and regulatory impact review for Atlantic sea scallops (Placopecten magellanicus). New England Fisheries Management Council. 
NEFMC (New England Fisheries Management Council). 2003. Amendment \#10 to the Atlantic sea scallop fishery management plan with a supplemental environmental impact statement, regulatory impact review, and regulatory flexibility analysis. New England Fisheries Management Council.

NEFSC (Northeast Fisheries Science Center). 2004. 39th Northeast Regional Stock Assessment Workshop (39th SAW) Assessment Summary Report. US Dep. Commer., Northeast Fish. Sci. Cent. Ref. Doc. 04-10. 239 pp.

NEFSC (Northeast Fisheries Science Center). 2007. 45th Northeast Regional Stock Assessment Workshop (45th SAW) Assessment Summary Report. US Dept. Comm. Northeast Fish. Sci. Cent. Ref. Doc. 07-16. $370 \mathrm{pp}$.

Revill, A. \& R. Holst. 2004. The selective properties of some sieve nets. Fish. Res. 66:171-183.

Rudders, D. B., W. D. DuPaul \& J. E. Kirkley. 1998. A comparison of size selectivity and relative efficiency of sea scallop trawls and dredges. Virginia Marine Resource Report No. 98-6.
Rudders, D. B., W. D. DuPaul \& J. E. Kirkley. 2000. A comparison of size selectivity and relative efficiency of sea scallop, Placopecten magellanicus (Gmelin, 1791), trawls and dredges. J. Shellfish Res. 19:757-764.

Serchuk, F. M. \& R. J. Smolowitz. 1980. Size selection of sea scallops by an offshore scallop survey dredge. International Council for the exploration of the sea. ICES Counc. Meet. Pap. 1980/K:24. Shellfish committee.

Van Voorhees, D. 2007. Fisheries of the United States, 2006. NMFS Office of Science and Technology, Fisheries Statistics Division.

Wileman, D. A., R. S. T. Ferro, R. Fonteyne \& R. B. Millar. 1996. Manual of methods of measuring the selectivity of towed fishing gears. ICES Coop. Res. Rep. No. 215. Copenhagen. 126 pp.

Xu, X. \& R. B. Millar. 1993. Estimation of trap selectivity for male snow crab (Chionectes opilio) using the SELECT modeling approach with unequal sampling effort. Can. J. Fish. Aquat. Sci. 50: 2485-2490. 